\title{
Case studies of hybrid and galvanic systems on bridge structures
}

\author{
Christian Stone $^{1}$, Michel Donadio ${ }^{2}$, Christian Christodoulou ${ }^{3}$, and Nigel Davison ${ }^{1}$ \\ ${ }^{I}$ Concrete Preservation Technologies, Long Eaton, Nottinghamshire, UK \\ ${ }^{2}$ Sika, Refurbishment, Le Bourget, Hauts-de-France, France \\ ${ }^{3}$ AECOM Ltd, Birmingham, U.K
}

\begin{abstract}
Corrosion of steel in bridge structures is a growing issue worldwide. Case studies of galvanic and hybrid systems show the diverse range of challenges and corrosion hazards that are faced during the design of these systems. Data from these case studies show the effectiveness of this approach. Hybrid systems have been utilised in controlling corrosion during refurbishment work on bridges for over a decade. Galvanic systems have been around much longer. By utilising these systems individually or together there is great flexibility in design. This allows intensive concrete restoration from a hybrid system alongside the maintenance of repairs in lower risk areas from galvanic anodes. This paper presents case studies covering hybrid and galvanic systems applied to bridge structures. Included is a prestressed concrete bridge in a tidal environment, we believe to be the first of its kind fitted with a hybrid system. Tidal considerations and flooding are key challenges in corrosion mitigation. Data shows the systems are particularly effective in these transitory environments reacting rapidly to increased risk.
\end{abstract}

\section{Introduction}

Throughout the world, bridge structures are exposed to moisture, salt, and other corrosion hazards. NACE estimated in 2016 that corrosion costs the world $\$ 2.5$ trillion (USD) every year and corrosion prevention and management could save up to $\$ 875$ billion (USD) every year [1]. The implementation of sacrificial zinc-rich anodes in rebar-reinforced concrete structures was one of the cited examples of cost-effective corrosion management.

With many of the world's busiest commuter cities being located on coastlines where corrosion risks are particularly high, effective corrosion management and monitoring are essential to avoid more costly repairs. Galvanic systems have been used for two decades to increase the lifetime of repaired concrete on corroding structures [2]. New hybrid galvanic systems restore the concrete environment around the rebar minimising the need for concrete replacement which saves significant labour and reduces the time the structure is impacted by the work.

It has been over a decade since some of the first hybrid systems were first installed on bridge structures $[4,5]$ in Scotland. The challenges, designs, and results of such systems will be covered here, including the monitoring and testing of this and more recent structures fitted with hybrid and galvanic patch anodes. With the characteristic responsive behaviour alongside falling galvanic currents and rising steel potentials the effectiveness of these systems can be shown.

\section{Structures}

This work will be discussing the following structures:

\subsection{SH16, Whau river bridge}

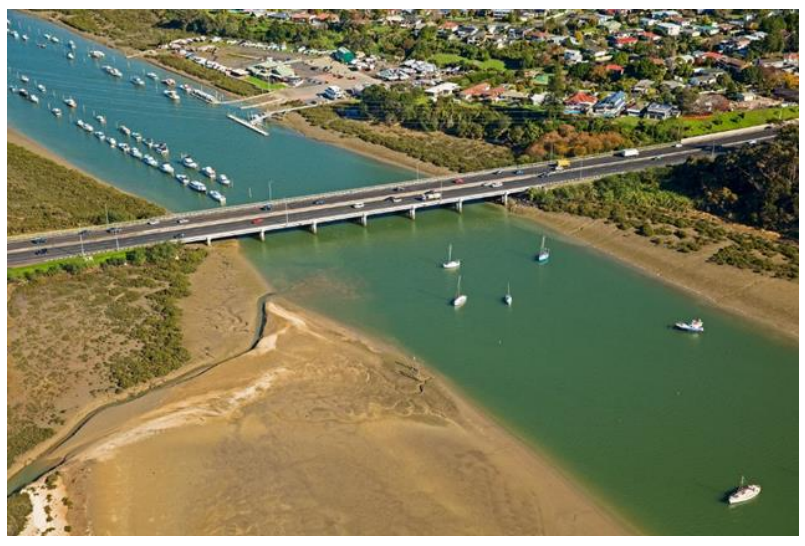

Fig. 1. Aerial view of the existing Whau River Bridge, looking south-west (Corbett \& Watterson, 2016 [6])

A $182 \mathrm{~m}$ long, eight-span bridge bringing traffic across the Whau River. Constructed in stages from the 1950s through to the 1990s, connecting Auckland to the city's western outskirts. The bridge is part of the SH16 which carries an average of 90,000 vehicles per day through an environmentally sensitive coastal reserve [7].

The superstructure consists of reinforced concrete supports with cast reinforced deck beams and deck slabs. 
The substructure varies across the bridge, the result of many expansions and alterations.

\subsection{SH16, Oakley causeway bridge}

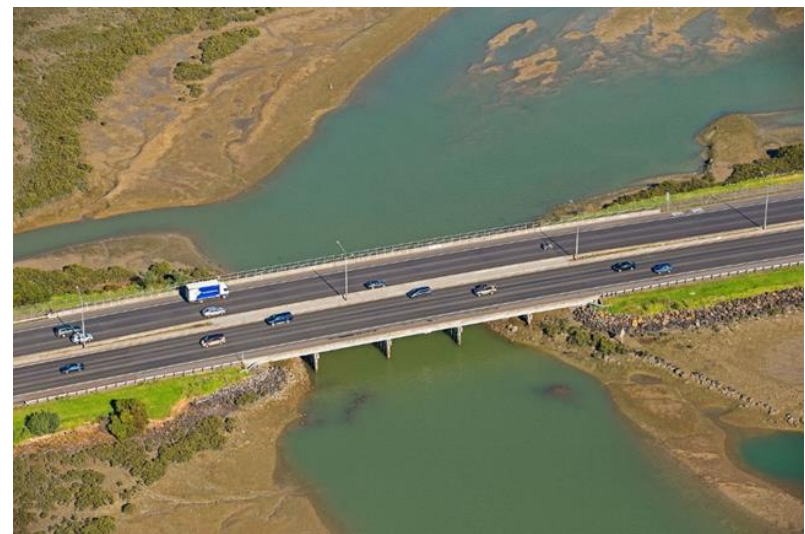

Fig. 2. Aerial view of the existing Causeway Bridge, looking south-west (Corbett \& Watterson, 2016 [6])

A 75m long, five-span bridge that brings SH16 traffic over the Oakley inlet waterway close to the Whau River bridge. Originally constructed in the 1950s this structure, like the Whau River bridge, has undergone widening and other alterations into the 1990s. This structure includes pre-tensioned concrete piles from both the 1960s structures and 1990s widening [7].

\subsection{B6461, Whiteadder bridge}

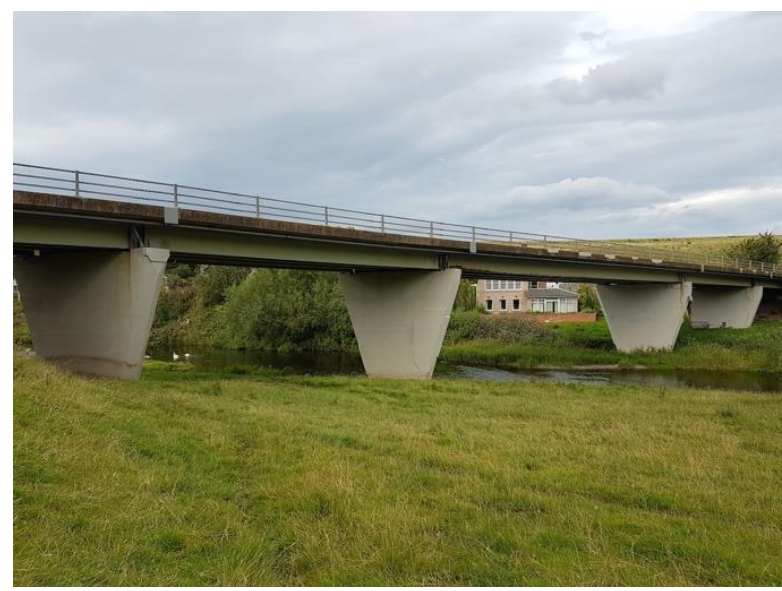

Fig. 3. Whiteadder bridge, Scotland, taken 10 years after installation

A $90 \mathrm{~m}$ single carriageway bridge structure constructed from steel girders supported on bearings directly above 4 trapezoidal reinforced concrete piers, the deck is constructed from reinforced concrete beams spanning horizontally between the four primary steel girders. The unique shape of the piers leads to steel density increasing towards to bottom. Built in 1973, it carries motor traffic over a tributary flowing into the river tweed which is prone to flooding [8].

\subsection{H6 canal bridge, Milton Keynes}

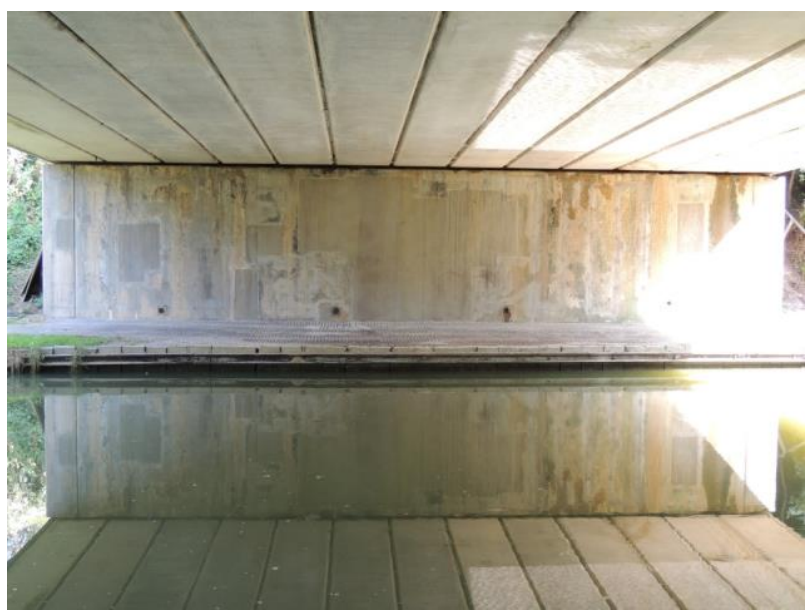

Fig. 4. Abutment shown from opposing bank 4 years after patch repairs

A $1970 \mathrm{~s} 14 \mathrm{~m}$ bridge carrying traffic via a dual carriageway over the canal in central Milton Keynes. Reinforced abutments support the concrete deck that spans the waterway. Leaking bridge joints resulted in contamination and corrosion in the abutments.

\section{Assessment}

This covers the assessment of both the SH16 causeway and river bridges. The structures underwent the following tests:

- Both SH16 structures above underwent full durability assessments utilizing mathematic models to predict the condition in 50 years' time.

- Visual inspection;

- Chloride depth profile sampling;

- Colorimetric carbonation depth testing;

- Compressive strength testing;

- Cement content testing;

- Reinforcement continuity;

- Resistivity of the concrete;

The Whau river bridge piles exhibited cracking, delamination, spalling and section loss. Chloride ion concentrations varied from 0.02 to $0.32 \%$ by weight of concrete, the standard allows for $0.06 \%$ or $0.03 \%$ by weight of concrete for plain and pre-stressed steel respectively [2]. Chloride concentrations were concluded to be the major cause of deterioration in this structure. These levels alone are a high enough risk to warrant an intervention.

Colorimetric testing showed no risk of carbonation at the depth of the steel, typically finding carbonation depths from $1-3 \mathrm{~mm}$ with only one outlier measurement of $23 \mathrm{~mm}$. The reinforcement depth varied from $40-80 \mathrm{~mm}$ in the piles depending on the age of the concrete.

The Oakley causeway bridge piles were in a similar state of deterioration as the Whau River bridge with chloride concentrations ranging from 0.02 to $0.25 \%$ by weight of concrete. Calculations using predictive modelling based on Fick's second Law [ASTM C1556 - 
04 and NZTA Report 337] which gives an idea of the time to corrosion initiation. These confirm the chloride levels are most likely the cause of the corrosion on both structures.

Whiteadder bridge and the H6 canal bridge had suffered severe delamination with exposed steel visible in areas. Both bridges underwent the following tests to assess the structures:

- Visual inspection;

- Chloride depth profile sampling;

- Colorimetric carbonation depth testing;

- Cement content testing;

- Reinforcement continuity;

- 2D potential mapping;

Whiteadder bridge showed substantial spalling and delamination on the piers from what appeared to be chloride ingress caused by leaking deck joints. Salt deposits were visible on the surface in some areas. The high concentration of chlorides was confirmed through testing a variety of locations by drilling in sections to the depth of the steel and collecting dust for analysis. The highest chloride ion content was found in two locations on a pier on the west side of the river. It measured 1.68\% chloride by weight of cement, a high risk of chlorideinduced corrosion. The half-cell potential map confirmed the high risk of corrosion and gave information that would allow the targeting of known, local anodic areas within the structure.

Visual inspection of the H6 canal bridge showed visible signs of chloride induced pitting on the exposed steel and the source of chloride appeared, from staining patterns, to be a leaking bridge joint allowing salt from the road above to be carried down through seepage. Through chemical analysis, it became clear that chloride was the instigator of the corrosion. Being by a canal the environment was very humid leading to widespread corrosion. The 2D potential map showed large anodic areas in need of protection.

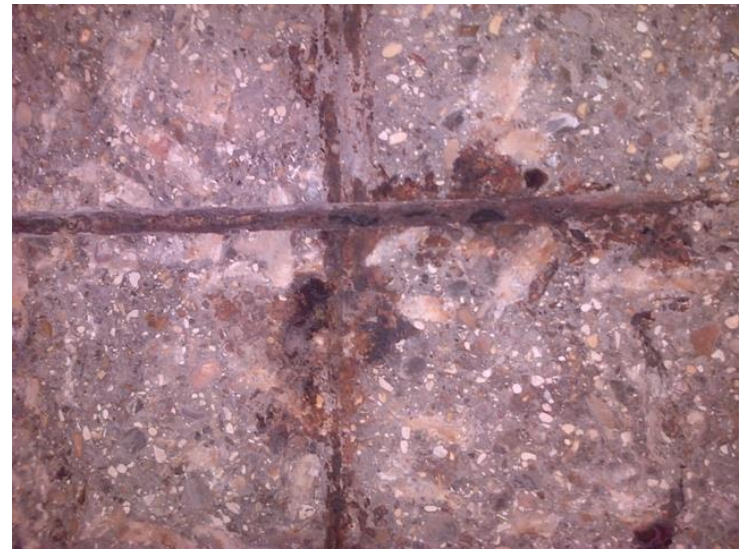

Fig. 5. Chloride pitting on the steel broken out during the repair of $\mathrm{H} 6$ canal bridge

\section{Corrosion prevention systems}

\subsection{Galvanic systems}

Galvanic systems utilise the electrochemical potential difference between two dissimilar metals to drive the protection of the steel. It is well known that anodic metals have more available ions and are therefore more energetically favourable to corrode. By adding a material that is less noble than steel to the concrete environment (commonly zinc) and connecting it to the reinforcement via a wire, charge can flow and a dissimilar metal couple is created which pushes the steel into a cathodic, protected state. The less noble material becomes an anode and corrodes sacrificially to supply electrons to the cathode protecting the steel during times of increased corrosion risk.

At the anode the material will tend to undergo oxidation reactions:

$$
\begin{gathered}
\mathrm{Zn} \rightarrow \mathrm{Zn}^{2+}+2 e^{-} \\
\mathrm{Zn}^{2+}+2 \mathrm{H}_{2} \mathrm{O} \rightleftharpoons \mathrm{Zn}(\mathrm{OH})_{2}+2 \mathrm{H}^{+}
\end{gathered}
$$

The electrons produced by this dissolution polarise the steel, protecting it from corrosion. These electrons fuel reduction reactions at the steel surface:

$$
\mathrm{O}_{2}+4 e^{-}+2 \mathrm{H}_{2} \mathrm{O} \rightarrow 4 \mathrm{OH}^{-}
$$

Oxygen and water in the pores of the concrete react on the rebar surface to produce alkaline hydroxide ions. [2]

Steel is not just protected by its polarisation; new concrete has a naturally high $\mathrm{pH}$ which protects the steel from corrosion. Carbonation and chloride ions decrease the $\mathrm{pH}$ environment of the steel making the steel vulnerable to anodic corrosion. An effective way of managing corrosion is to restore and maintain the concrete around the steel. The cathodic steel uses electrons to create an alkaline hydroxide environment. These ions restore the $\mathrm{pH}$ of the concrete. Once the $\mathrm{pH}$ gets high enough the steel will passivate, and corrosion will be managed. [14]

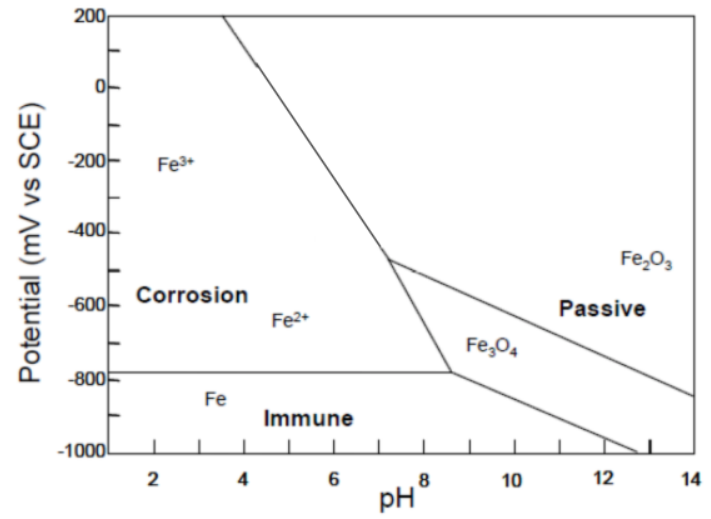

Fig. 6. Simplified Pourbaix diagram of iron

The anode and steel system act as a cell with a driving voltage defined by the electrochemical galvanic potential difference between the two metals. This cell produces a current based on the resistivity of the concrete electrolyte and the corrosion of the anode. The resistivity is dependent on the moisture levels in the concrete and the 
anodic corrosion is dependent on the presence of corrosion hazards such as water, oxygen, heat and chloride. Therefore, the cell is producing the most current during times of high corrosion risk. The anodes can be said to work reactively in response to hazards [8]. When galvanic anodes are installed it is common to soak the concrete. This gives the system an initial surge of current to halt ongoing corrosion. As the anode corrodes to protect the steel it is, like any cell slowly depleted, making lifetime calculations using predicted currents a key part of system design.

Galvanic systems are very effective for maintaining systems such as patch repairs and low chloride content concrete. They are however limited in the power they can provide by the surface area of the anode and the resistivity of the concrete. Galvanic anodes are typically used on the edges of patch repairs or in arrays throughout low-risk or repaired concrete. Though galvanic anodes can and do restore the concrete environment, their limited current makes them a poor choice in heavily contaminated areas. These areas are best served by impressed current or hybrid systems.

\subsection{Impressed current systems}

Impressed current cathodic protection (ICCP) systems will not be covered here in detail. ICCP systems have commonly been used to polarise steel in contaminated concrete by driving a current larger than that typically seen in galvanic systems through titanium ribbons, mesh or inert discrete anodes [15] reversing the direction of the current produced by corrosion. This reduces the need for replacing much of the concrete.

ICCP systems are typically held at constant current utilising a transformed and regulated mains electricity connection to provide protection for the lifetime of the system. The systems need frequent adjusting and monitoring; too high a current and the acid formed at the inert anode will start to locally dissolve the concrete, too low and the steel will not be adequately polarised. The running costs of these systems sometimes lead to them being turned off. It has been shown that when turned off the steel depolarises, but corrosion does not initiate for some time. This is due to the restoration of the steel environment $[16,17,18]$.

The current driven to the steel generates a hydroxide bath through reduction at the steel interface, restoring the $\mathrm{pH}$ and the positively charge anodes pull harmful chloride ions away from the reinforcement. This restored environment keeps the steel passive.

\subsection{Hybrid systems}

Hybrid anodes were developed as the best of both worlds, combining a short, high intensity impressed current phase to restore the concrete environment with the long term, low maintenance responsivity of a galvanic system. Rather than using inert ICCP anode, hybrid systems supply the initial current through the same galvanic anodes as the second protective phase. The in-situ anodes then maintain the restored environment for the lifetime of the system. This protection comes without the need for the permanent housing of a large and complicated powering system and the corresponding large running cost and vandalism risk.

Like galvanic systems, discrete zinc anodes are embedded into pre-drilled cavities within the concrete. Hybrid anodes are arranged in regular arrays spaced according to the density of the steel reinforcement used. The anodes comprise zinc cylinders $25-220 \mathrm{~mm}$ long with a coating designed to keep the anode active during its design life. Like ICCP systems these anodes have a titanium wire connector, better suited to delivering an impressed current.

During the initial impressed phase, power is typically driven from a $9 \mathrm{~V}$ power supply providing the $50 \mathrm{kC} / \mathrm{m}^{2}$ of steel surface area charge needed to restore passivity $[3,4]$ The current is often much larger than ICCP systems which are limited to $110 \mathrm{~mA}$ but given the coatings typically used on the anodes and the short time scale of this phase, acid is not able to accumulate.

After adequate charge has been provided to the steel, typically a few weeks, the power source is removed, and the anodes are connected directly to the steel to start galvanic protection. During the galvanic phase, currents will vary responding to moisture and other corrosion risk factors.

The combination of hybrid and galvanic systems into highly contaminated and low contamination zones respectively allows for the creation of low running cost corrosion management systems that react to the corrosion hazards in the structure's environment and can be effectively monitored with embedded reference electrodes over the lifetime of the structure.

\section{System Design}

\subsection{SH16 Whau river and Oakley causeway bridges}

These structures had a variety of steel depths on the piers as well as other challenges to factor in during the design phase. A major factor in the choice of the cathodic protection system was using a system that could be installed in a short amount of time and with access constraints dependent on the nature of tides in the marine environment. Hybrid anodes are well suited in part due to their fast and straight-forward installation with a simple and easy wiring design.

Pre-stressed steel structures offer many advantages for a large concrete structure but can suffer from hydrogen embrittlement when protected with an impressed current. If the current is too high and the steel potential is driven too low the steel will start to embrittle which could put the entire structure at risk. Care must be taken providing a high current to pre-stressed steel but as long as polarisation rates do not stray more negative than $-900 \mathrm{mV}$ vs SCE for an extended period of time there is little risk of embrittlement. Galvanic anodes are naturally limited in voltage by the dissimilar metal couple and do not suffer from this problem in concrete. 
As these structures are exposed to seawater in a tidal area there are three major zones to consider on the piles:

- Atmospheric zone; from the soffit to $1 \mathrm{~m}$ above the highest tide mark;

- Splash zone; from $0.5 \mathrm{~m}$ above the average high tide to $1 \mathrm{~m}$ above the highest tide;

- Tidal zone; from mean low water springs to $0.5 \mathrm{~m}$ above the average high tide;

Protection below this point is in this case was not deemed necessary, in part due to the sparsity of oxygen in a marine environment limiting corrosion.

Hybrid anodes, with capacities exceeding $300 \mathrm{kC}$, manufactured using $18 \mathrm{~mm}$ zinc cylinders and length 165$220 \mathrm{~mm}$ were then installed into predrilled holes using an activated proprietary ready-to-use mortar around the anodes and a high-quality low-shrinkage repair mortar to cap the hole. The titanium connector wires were embedded in chases between the anodes to allow a current to be impressed via a junction box housed on the abutments of each bridge. This junction box also contained a connection to the steel reinforcement and a data logging system.

A manganese Oxide reference electrode was used to record continual monitoring data, measuring the steel potential, anode current, and corrosion current density from polarisation resistance. These are used to calculate both the steel polarisation and corrosion rate which can be used to assess the corrosion risk.

\subsection{Whiteadder bridge}

Regular flooding, splash zones, steel density changes, and tidal effects all play a part in the unique challenges of designing this system. Leaking from the joints also allowed, during the winter, chloride rich water to seep into the piers from above. It was determined that the design and the monitoring should be in two zones. An upper 'dry' zone and a lower 'wet' zone.

Cylindrical zinc hybrid anodes of $18 \mathrm{~mm}$ diameter, ranging from 25 to $220 \mathrm{~mm}$ in length, with an integrated titanium connector wire, were installed with a separation of $400 \mathrm{~mm}$ for the lower zones and $500 \mathrm{~mm}$ for the upper zone over the surface of 4 reinforced piers. The anodes were placed closer in the lower zones to combat the higher density of steel in that area. Reference electrodes were embedded in upper and lower zones on the piers in 12 locations. Ten rows of five hybrid anodes were installed in the monitored area. The upper zones were known to be dry, outside of flood or tidal splash zones. The lower zones would be in areas with more moisture. A wireless modem powered by a battery which could be recharged from a solar panel allowed remote access via a desktop PC. Data samples were taken every 6 hours.

\subsection{H6 canal bridge}

Galvanic anodes were embedded about $400 \mathrm{~mm}$ apart around the patch repairs in the parent concrete on the abutment. The anodes were directly connected to the reinforcement. The anode capacity and density over the abutment depended on the risk, with a higher density located adjacent to the repair areas and in wet areas arising from the leaking joints. The deck joints were not repaired and continued to leak after the anode installation.

\section{Results}

\subsection{Initial testing of Whau River and Oakley causeway bridge}

Following installation, the hybrid systems were connected to the power source and energised to deliver the $50 \mathrm{kC} / \mathrm{m}^{2}$ of charge to the steel reinforcement. Data showing the polarisation of the reinforcement up to $50 \mathrm{kC} / \mathrm{m}^{2}$ of steel surface area and the current applied to a single zone are shown below:

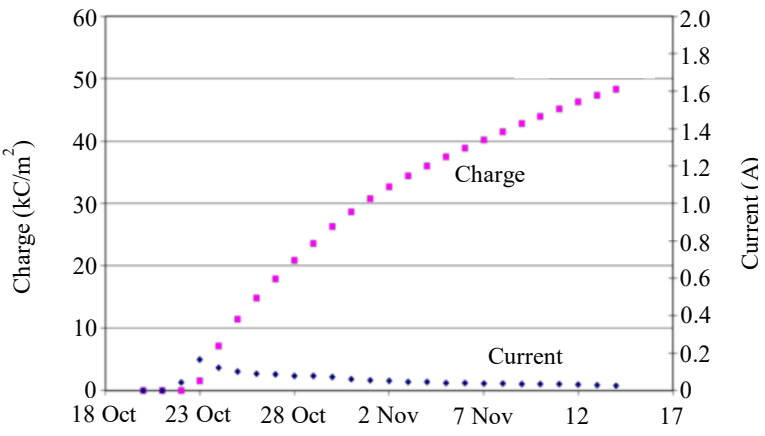

Fig. 7. Typical charge density and current applied to a zone [7]

After completing the impressed current phase, the system is tested using a depolarisation test as stated in the ISO 12696:2016 standard. Below is shown the depolarisation test data for atmospheric and splash zones:

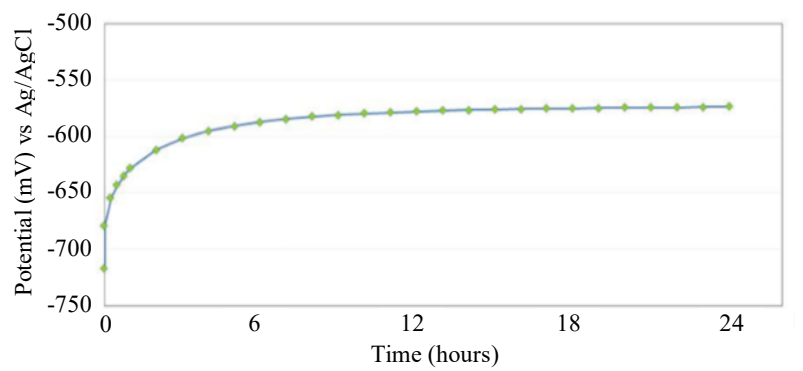

Fig. 8. Depolarisation taken in an atmospheric zone [7]

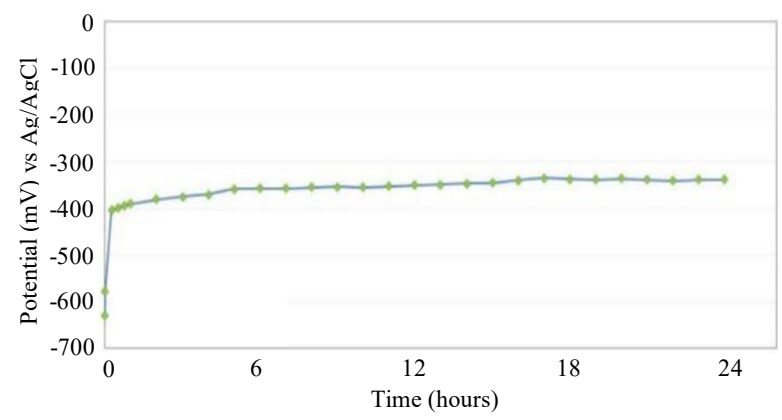

Fig. 9. Depolarisation taken in a splash zone [7]

It can be seen that a depolarisation greater that $100 \mathrm{mV}$ over $24 \mathrm{hrs}$ has been achieved for the both zones. The steel is therefore seen to have sufficient cathodic protection. In 
the splash zone, a greater polarisation potential of $240 \mathrm{mV}$ is measured over $24 \mathrm{hrs}$. In these zones, the steel has been passivated during the impressed current phase and the steel is completely protected by the anodes.

Tidal zones may not be able to be assessed in the same manner given the changing conditions from the sea water level rising and falling during the depolarisation test and complications caused by oxygen depletion when there is a variety of steel potentials. However, the data indicates quite clearly the responsive nature of the anodes to corrosion hazards.

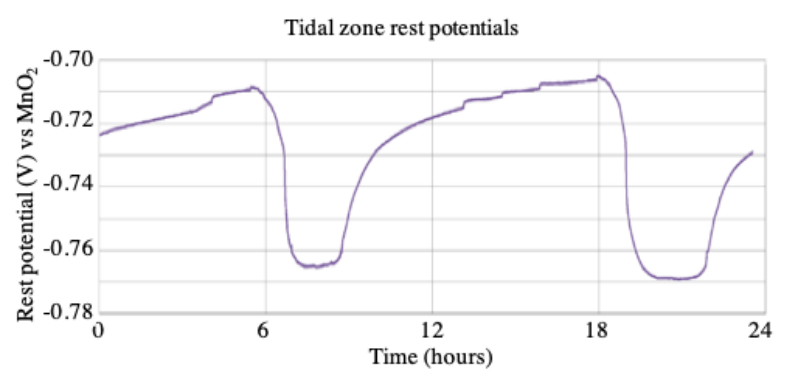

Fig. 7. Rest potentials in a tidal zone [7]

As shown above, the drop seen in potential during low and high tide is $40-65 \mathrm{mV}$ over approximately 9 hours across the piers. This changing environment will limit the ability to do standard depolarisation tests. Instead, calculated corrosion rates for the areas will be used.

The Bulter-Volmer equation gives a way of calculating a corrosion risk that can be assessed as a corrosion risk factor. Corrosion rates greater than $2 \mathrm{~mA} / \mathrm{m}^{2}$ are typically associated with some corrosion risk. Though, higher but falling corrosion rates in an area also show protection in the standard ISO12696:2016, because of this it is recommended to keep a $\log$ of data for historical comparison.

Given the measured corrosion rates fall below the threshold for corrosion risk and clearly rising steel potentials in the tidal zones, protection can be said to have been achieved.

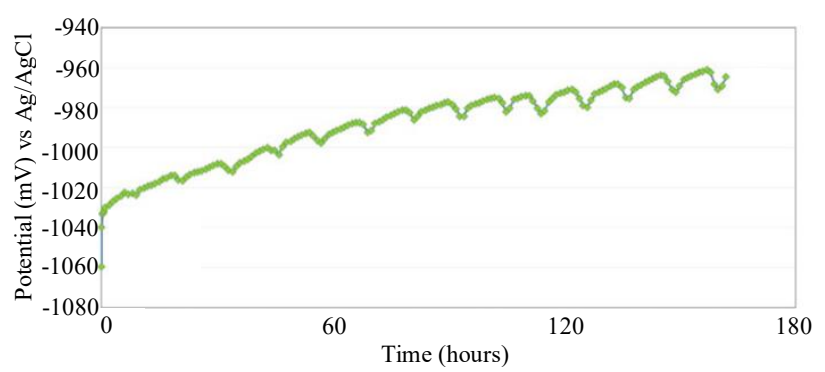

Fig. 8. Depolarisation of a tidal zone over 160 hours [7]

\subsection{Monitoring of $\mathrm{H} 6$ canal bridge and Whiteadder bridge}

Patch protection and hybrid systems tend to have different intensities of monitoring. The $\mathrm{H} 6$ canal bridge project was installed as a low maintenance system and therefore had no in-built reference electrodes. The Whiteadder project, by contrast, had continual monitoring taking data several times a day to allow off-site employees to monitor the system remotely.
After 4 years, the H6 canal bridge underwent a visual inspection and a surface half-cell potential measurement using a calibrated copper sulphate electrode with a steel connection to the local reinforcement. Examination of the structure shows that there was no concrete delamination or cracking despite the continued contamination with salt water from the failed joint on the bridge above:

Potential testing was undertaken at small intervals along the concrete to determine if those anodes could be identified after 4 years of operation. A half-cell electrode was placed on the concrete surface at regular intervals in the vicinity of the installed galvanic anodes embedded in the host concrete to generate a local 'potential map'.

When potential measurements are taken with respect to the reinforcement, a large negative potential indicates an anodic area. Therefore, when potential maps are taken, the most negative areas should be the sacrificial galvanic anodes that were embedded. Areas of negative potential away from the anodes will point towards possible corroding anodic steel, these areas will be likely exposed to increased chloride or moisture levels.

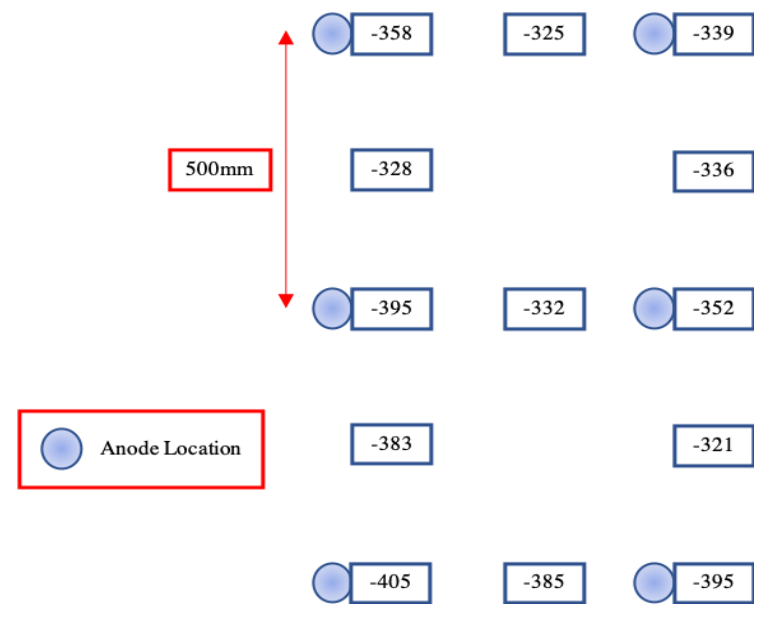

Fig. 9. Half-cell potential data from Test Area 1 (in mV v CSE)

It can be seen that the galvanic anodes can be clearly identified by measuring surface half-cell potentials i.e. the most anodic areas are associated with the installed galvanic anodes - this confirms that the anodes continue to generate current and are polarising the steel such that this can be measured on site. This also confirms that the steel has the least negative potential and as it is relatively cathodic and being protected by the sacrificial anodes.

A close interval half-cell potential test was undertaken at $50 \mathrm{~mm}$ centres along the edge of the large repair in the centre of the bridge and data was obtained as follows;

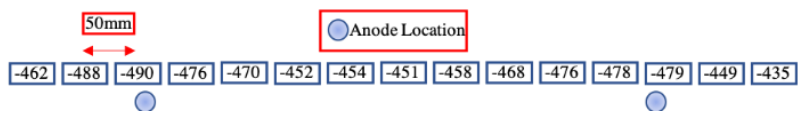

Fig. 10. Very Close Interval Half-cell potential data from Test Area 2 (in $\mathrm{mV}$ v CSE)

The half-cell potential rises adjacent to the anode and drops off moving away from the anode location indicating 
the sacrificial anodes are active and offering protection to the more cathodic steel.

A further area was tested around the large central patch, as follows;

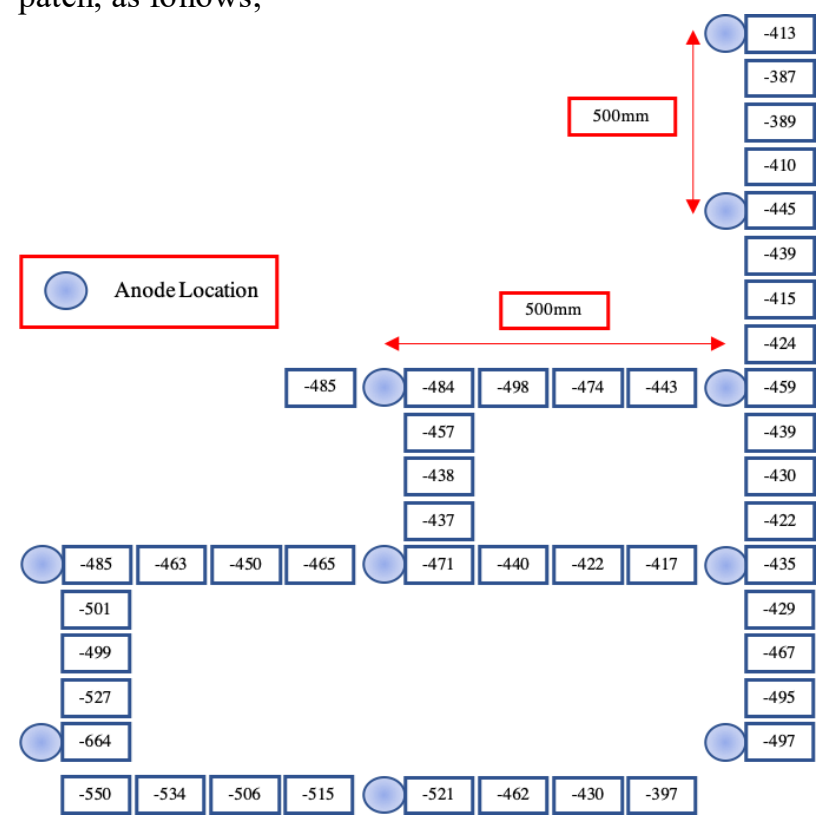

Fig. 11. Half-cell potential map from Test Area 3 (in $\mathrm{mV} v$ CSE)

Data from test area 3 was obtained from the bottom of the bridge structure adjacent to the large patch repair and shows that the anodes again can be identified from surface half-cell potential measurements. In addition, one of the anodes at the base of the structure is at a very negative potential $(-664 \mathrm{mV})$ indicating greater activity in an area where moisture levels are higher. It is clear that potentials generally get more negative on moving towards the bottom of the structure where there is more moisture and sacrificial anode activity is higher. This demonstrates the responsive behaviour of sacrificial anodes which generate current when the moisture content, and therefore the tendency for higher corrosion risk increases. The anode systems are functioning well to control corrosion and respond to moisture levels from both the canal and saltladen water from the bridge above.

Whiteadder bridge was one of the first structures in the world to be fitted with a hybrid anode system. After 8 years AECOM did an independent study of the site over 2 years [4]. A waterproofing membrane added after installation limits the ability to do effective potential mapping. However, reference electrodes were placed in both upper 'dry' zones and lower 'wet' zones with data collected several times a day. Polarisation tests were done throughout the life of the project.

A visual inspection was carried out in March 2014, 8 years after installation. Although there was discolouration on the piers arising from the leaking deck joints above, no visible defects were found.

The initial current generated by the anodes after the end of the impressed current phase is quite high because of the moisture in the embedding mortar. The current then reduces as the mortar dries until it reaches a steady, low, maintenance current, this steady state current represents the work done to maintain the system once the local concrete environment is restored. Like the bridges in New Zealand, there is a clear difference between the 'wet' lower and 'dry' upper zones. A larger current is drawn in the 'wet' zone due to the lower resistivity of the concrete which protects against the increased risk from the moisture.

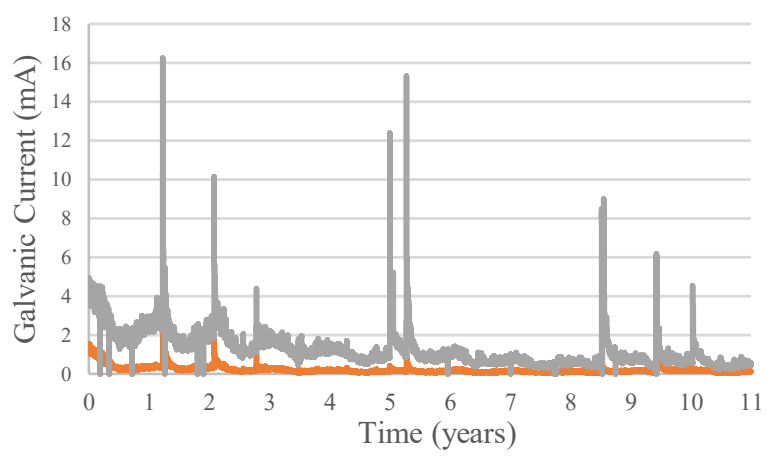

Fig. 12. Galvanic currents in upper and lower zones of Whiteadder bridge over 11 years

This is the most recent data for Whiteadder. Large peaks, an order of magnitude greater than the steady-state, can be seen at irregular intervals over the 11 years of data. These peaks are reactions to the river flooding with the rise mainly seen in the lower zone. The system is working well to protect the steel increasing the current reactively during a period of high risk until the moisture levels and resistivity drop back to normal.

A noticeable swell in the galvanic current can be seen every year. The swell is highest in the summertime and lowest during the winter months. This is the result of temperature variation during the year increasing the ionic mobility and with it, the work needed to maintain the concrete. This responsive behaviour shows that the system is actively working to protect the steel.

Galvanic systems aim to maintain the environment rather than polarising the steel, therefore corrosion current density calculations are used to get an accurate impression of the state of corrosion. The following table shows the first eight years of average current output for both upper 'dry' zones and lower 'wet' zones.

Tab. 1. Average current output (mA) for the first 8 years of operation [4]

\begin{tabular}{|l|l|l|}
\hline \multirow{2}{*}{ Year } & \multicolumn{2}{|l|}{ Average Anode Current Output (mA) } \\
\cline { 2 - 3 } & Upper Zone & Lower Zone \\
\hline 1 & 0.5 & 2.52 \\
\hline 2 & 0.42 & 2.22 \\
\hline 3 & 0.27 & 1.8 \\
\hline 4 & 0.17 & 1.29 \\
\hline 5 & 0.13 & 0.95 \\
\hline 6 & 0.16 & 1.39 \\
\hline 7 & 0.12 & 0.72 \\
\hline 8 & 0.11 & 0.74 \\
\hline 8 -year average & 0.24 & 1.45 \\
\hline
\end{tabular}

Both the upper and lower zones have falling average anodic currents with 8 -year averages. When polarisation 
tests were used to calculate corrosion rates, the lower zone falls well within the design current density of $2 \mathrm{~mA} / \mathrm{m}^{2}$ and met the threshold for satisfying the low corrosion risk criteria. The upper zone has a natural variance depending on the depolarisation over the 6 test sites.

Tab. 2. Corrosion rate measurements using the area protected by the monitoring zone as $0.7 \mathrm{~m}^{2}$, an approximate steel density of $1.95 \mathrm{~m}^{2}$ and $2.05 \mathrm{~m}^{2}$ per $\mathrm{m}^{2}$ of concrete for upper and lower zones respectively over an 8-year period [4]

\begin{tabular}{|l|l|l}
\hline \multirow{2}{*}{ Date } & \multicolumn{2}{|l}{ Corrosion Rate $\left(\mathrm{mA} / \mathrm{m}^{2}\right)$} \\
\cline { 2 - 3 } & Upper Zone & Lower Zone \\
\hline $19 / 04 / 07$ & 1.89 & 0.67 \\
\hline $27 / 08 / 07$ & 2.48 & 0.66 \\
\hline $20 / 10 / 07$ & 1.74 & 0.43 \\
\hline $06 / 03 / 08$ & 2.38 & 0.49 \\
\hline $12 / 05 / 09$ & 2.88 & 0.47 \\
\hline $04 / 06 / 13$ & 2.07 & 0.45 \\
\hline $20 / 06 / 14$ & 2.47 & 0.46 \\
\hline $12 / 03 / 15$ & 1.60 & 0.24 \\
\hline
\end{tabular}

Further proof of adequate protection is given by the migration of the steel potentials towards more positive values, a sign of the steel passivity. The dips correspond to the same flooding events seen before which caused responsive behaviour from the anodes. Given that after 8 years the corrosion rate was calculated at $1.60 \mathrm{~mA} / \mathrm{m}^{2}$ coupled with the rising potential of the steel, it was determined that adequate protection had been given.

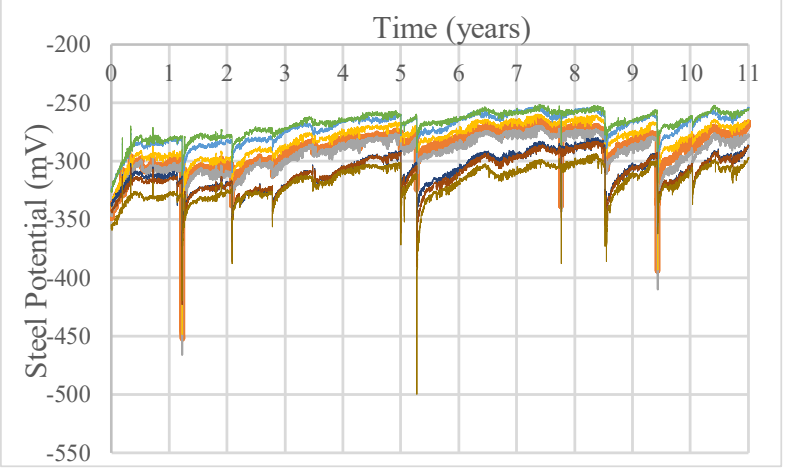

Fig. 13. Steel potentials data over 11 years [4]

There is a strong correlation between the anode current and steel potential values. As the potentials tend more positive the anodic current tends towards lower values as the demand is reduced by the benign environment of the steel. During the flooding events, near instantaneous reactions are observed to both the anodic current and the steel potential, showing that even after many years the galvanic system remains active and responds to higher corrosion risk by preferentially corroding and polarising the steel.

\section{Conclusions}

The responsive behaviour of galvanic anodes makes them uniquely suited to the transitory environments found on bridges or other river and marine structures worldwide. Whether the water source be from humidity, a canal, flooding, rainfall, or salinated from salt laden water seeping through leaking joints, galvanic anodes respond to the corrosion risk to protect the steel reinforcement.

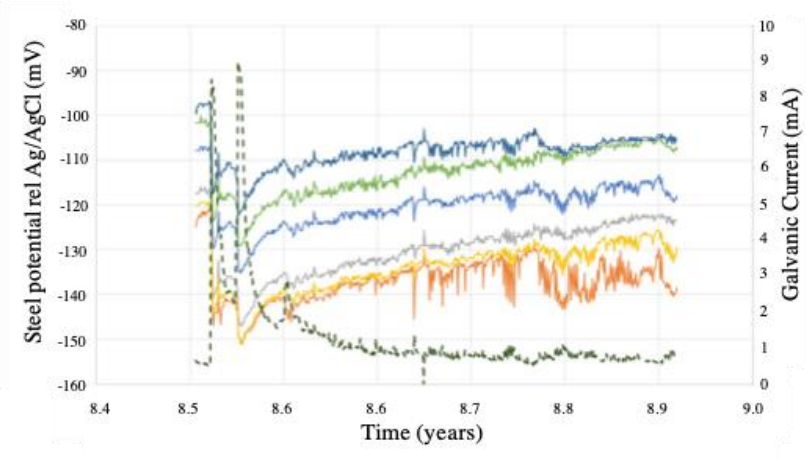

Fig. 14. Response of steel potential and galvanic current to a flooding event [4]

This reactive, self-regulating system therefore only provides high currents in response to corrosion hazards increasing the lifetime of the system. Whiteadder bridge was designed for a 30-year lifetime and was guaranteed for 20 years but is currently on track to have a usable lifetime in excess of 50 years $[4,8]$

On the earliest installed hybrid system, we see this responsive behaviour active over its first 11 years of life, with calculations showing that the anodes have many decades of lifetime remaining. This is due to the anodes having very low corrosion currents when there is little moisture present and little risk of corrosion. The lowest corrosion rates, in fact, were calculated from data recorded in the highest risk areas.

Galvanic systems are well suited to dealing with sudden changes in environment such as flooding, rainfall, and tides, instantly increasing protection during the event and maintaining adequate protection during the high risk drying out period.

On the H6 canal bridge we see that anodes react locally to risk, only active in areas with high moisture to prevent the steel corroding. Using this knowledge, structures may be designed to use larger capacity anodes in higher risk areas, increasing the design life of the project efficiently.

The SH16 bridges are the first utilisation of a hybrid system on a pre-stressed structure. Care must be taken during the short impressed current phase not to exceed the hydrogen embrittlement threshold for an extended period. However, due to the fixed driving voltage of the galvanic anodes during the galvanic phase there is no risk of hydrogen embrittlement.

Concrete environment restoration, temporal and local responsivity alongside a fixed safe voltage for prestressed structures make hybrid and galvanic anodes a great solution for corrosion on bridges and waterways. The simple installation and straightforward implementation are well suited to projects with limited and tidal access and the reactive nature of these anodes also allows for extended design lifetimes. Whiteadder bridge, the oldest structure is on-track to provide protection past its design life by 20 or more years. 


\section{References}

1. G. Koch, J. Varney, N. Thompson, et al, International measures of prevention, application, and economics of corrosion technologies study, NACE International, Impact.nace.org/documents/Nace-InternationalReport.pdf (2016).

2. C. Christodoulou, G. K. Glass, J. Webb, V. Ngala, S. Beamish, P. Gilbert, Evaluation of galvanic technologies available for bridge structures, In: Structural Faults and Repair, 12th International Conference and Exhibition. Engineering Technics Press, Edinburgh, UK (2008).

3. G. K. Glass, A. C. Roberts, N. Davison, Hybrid corrosion protection of chloride-contaminated concrete, Proceedings of the Institution of Civil Engineers-Construction Materials, 161, 163-172 (2008).

4. W. Dodds, C. Christodoulou, C. Goodier, Hybrid anode concrete corrosion protection - independent study, Proceedings of the Institution of Civil Engineers-Construction Materials, Ahead of Print, https://doi.org/10.1680/jcoma.16.00024 (2016).

5. G. K. Glass, A. C. Roberts, N. Davison, Assessment of cathodic protection applied to above ground reinforced concrete, Materials and Corrosion, 70 (3), 503-510, (2019).

6. T. J. Watterson, P. W. Corbett, Widening of existing bridges on State Highway 16 in Auckland. Proceedings of the ICE - Bridge Engineering. 169. 1-12. (2015).

7. C. Christodoulou, R. Cobbs, P. Corbett, and M. Elliot, Service life extension of state highway 16 bridges - New Zealand's first hybrid corrosion protection application, MATEC Web of Conferences 199, 05002 (2018).

8. C. Christodoulou, W. Dodds, B. Jackson, et al, Hybrid galvanic corrosion protection of Whiteadder Bridge - 10 years on, unpublished (2019).

9. Concrete Society, Technical Report 60, Electrochemical tests for reinforcement corrosion, Surrey, UK (2004).

10. U. Angst, B. Elsener, C.K Larsen, O. Vennesland, Critical chloride content in reinforced concrete - A review. Cement and Concrete Research, 39, 11221138 (2009).

11. ASTM C 1556 - 04

12. NZTA Report 337 - Deterioration of Prestressed Concrete Bridge Beams.

13. S. P. Holmes, The response of galvanic protection current to environmental changes, EUROCORR Nice, France, Paper 8254 (2009)

14. G. K. Glass, A. C. Roberts, N. Davison, Pit realkalisation and its role in the electrochemical repair of reinforced concrete, Journal of Corrosion Science and Engineering, 9, Paper 10, (2007).
15. ISO. 12696. Cathodic Protection of Steel in Concrete, (2016).

16. G. K. Glass, J. R. Chadwick, Corrosion Science, 36, 12, 2193-2209 (Dec. 1994).

17. C. Christodoulou, G. K. Glass, J. Webb, S. Austin, C. Goodier, Assessing the long term benefits of impressed current cathodic protection, Corrosion Science, 52, 2671-2679 (2010).

18. C. Christodoulou, A. Sharifi, S. Das, C. Goodier, Cathodic protection on the UK's Midland Links motorway viaducts, Proceedings of the Institution of Civil Engineers: Bridge Engineering, 167, 43 - 53 (2013). 